\title{
KARAKTERISTIK DAN ANALISIS KEKERABATAN RAGAM KELAPA (Cocos nucifera L.) DI KABUPATEN MANGGARAI BARAT BERDASARKAN KARAKTER MORFOLOGI DAN ANATOMI
}

\section{CHARACTERISTICS AND ANALYSIS OF COCONUT KERNELS (Cocos nucifera L.) IN WEST MANGGARAI BASED ON MORPHOLOGICAL AND ANATOMICAL CHARAKTERS}

\author{
Leonarda Gunawati, Eniek Kriwiyanti, Martin Joni \\ *Program Studi Biologi, Fakultas MIPA, Universitas Udayana, Bali \\ *Email : lengun94@gmail.com
}

\section{INTISARI}

Penelitian tentang karakteristik dan analisis kekerabatan ragam kelapa (Cocos nucifera L.) di Kabupaten Manggarai Barat telah dilakukan untuk mengetahui ada beberapa ragam, hubungan kekerabatan dan manfaat tanaman kelapa (Cocos nucifera L.). Eksplorasi tanaman kelapa (Cocos nucifera L.) dilakukan di Kabupaten Manggarai Barat, Flores dan pembuatan preparat dilakukan di Laboratorium Struktur Perkembangan Tumbuhan, dilaksanakan Februari-Juli 2016. Metode penelitian digunakan eksplorasi dan pengamatan dan pengukuran bagian tanaman untuk membuat deskripsi sesuai pedoman IPGR dan Buku Pusat Perlindungan Varietas Tanaman (PPVT 2007) kelapa (Cocos nucifera L.). Hasil pengamatan morfologi dan anatomi berupa data kualitatif dan kuantitatif untukmembuat kunci, kemudian diskor disajikan dalam bentuk tabel OTU (Operation Taksonomy Unit) untuk membuat dendogram dengan program Minitab vis 14. Hasil penelitian didapatkan delapan ragam tanaman kelapa (Cocos nucifera L.) yaitu Nio Kuse, Nio Taak Ngoel, Nio Sangon, Nio Taak Tua, Nio Bakok, Nio Ndereng, Nio Kuning dan Nio Lolo. Berdasarkan karakteristik morfologi dan anatomi daun pada tingkat kemiripan $(32,1 \%)$ kedelapan ragam kelapa di Kabupaten Manggarai Barat terpisah menjadi 8 kelompok (kultivar). Semua bagian tanaman kelapa memiliki manfaat ekonomi terutama buah kelapa Taak Tuamemiliki daging buah paling tebal $(1,7 \mathrm{~cm})$ dan Nio Sangonmemiliki buah paling berat $(2,6 \mathrm{~kg})$.

Kata Kunci: kekerabatan, eksplorasi, identifikasi, kualitatif, kuantitatif

\section{ABSTRACT}

Research on the characteristic and analysisof coconut kernels (Cocos nucifera L.) in west Manggarai district has been done to determine the variety, kinship and coconut plant benefits(Cocos nucifera L.).Cocos nucifera L. Exploration was conduction in west Manggarai - Flores regency and preparatory preparationwasdone in Plant Structure Development Laboratory, conducted from February to July 2016. Exploration was done by observation and to make the description according to Book Center for Plant Variety Protection (PPVT) 2007. (Cocos nucifera L.) morphological and anatomical observation results descriptive for identification. The discarded qualitative and quantitative dara are presented in OTU table (OperationTaksonomy Unit) to create a dendogram withMinitab program vis 14 . Research results the were eight varietas of coconut plants (Cocos nucifera L.) Nio Kuse, Nio Taak Tua, Nio Taak Ngoel, Nio Sangon, Nio Ndereng, Nio Kuning and Nio Lolo. Based on morphological and anatomical characteristics and at similarity level (32.1\%) eight coconuts in separate West Manggarai into 8 groups All parts of the coconut plant have economic benefits especially old coconut fruit has a thick fruit flesh $(1.7 \mathrm{~cm})$ and Nio Sangon has the $(2.6 \mathrm{~kg}$ weight

\section{Keywords : kinship, exploration, quantitative, qualitative, identification}

\section{PENDAHULUAN}

Kelapa adalah tanaman yang serba guna, karena memiliki keragaman kultivar yang tinggi. Seluruh bagian tanaman kelapa (Cocos nucifera L.) sangat bermanfaat bagi kehidupan manusia (Setyamidjaja, 1984). Tanaman kelapa ini, pada buah mulai dari kulit sampai air kelapa mempunyai fungsinya masing-masing.

Kelapa (Cocos nucifera L.) sebagai salah satu spesies dari genus Cocos dibedakan menjadi dua varietas yaitu kelapa Dalam (Cocos nucifera $\mathrm{L}$ var typica) dan Kelapa Genjah (Cocos nucifera L. nana Griff. Selain keelapa Semi Dalam (Cocos nucifera L. aurantiaca). Kelapa tipe Dalam memiliki tipe pohon dengan ukuran besar dibandingkan denga kelapa Genjah, kemudian salah satu tipe kelapa Dalam memiliki bole,, ukuran buahnya besar dan memiliki bunga umur 5 tahun, penyerbukkan lainnya silang. Kelapa Genjah ukuran buah lebih kecil, tidak memiliki bole, penyerbukkan sendiri, berbuah pada umur 3-5 Tahun. Sedangkan kelapa semi Dalam memiliki sifat diantara keduanya (Maskromo, 2000)

Hasil survei tim Balika Manado berhasil identifikasi 40 aksesi dan 11 diantaranya termasuk kelapa unik diantaranya kelapa buah besar ada tiga jenis, kemudian kelapa sabut tipis dan kelapa buahnya banyak 100, kelapa sabut merah dan satu kelapa kenari dengan daging buah yang renyah (Maskromo, 2000).

Hasil penelitian Yasa dan Kriswiyanti (2016) tentang kelapa Madan di kecamatan Manggis Kabupaten Karangasem ditemukan ada 18 ragam kelapa yang dibedakan berdasarkan karakteristik warna kulit buah, ada tidak bole, warna dan bentuk dari buah. Didapatkan tiga varietas yaitu kelapa Dalam, kelapa Genjah, dan kelapa Bluluk diantaranya ragamkelapa gadang, genjah, gading, udang, sidomala, mulung,julid, rangde, padma,bunga dan kelapa naga.

Manggarai Barat merupakan salah satu kabupaten di pulau Flores yang memiliki tanaman kelapa yang cukup banyak di sepanjang pante. Kelapa (Cocos nucifera L.) di Manggarai Barat disebut Nio. Namun, masyarakat di Manggarai Barat masih banyak yang belum mengetahui ragam dan manfaatnya. Oleh karena itu dilakukan untuk mengetahui erapa banyak ragam dan manfaat untuk ekonomi dari kelapa di Manggarai Barat. 


\section{METODE PENELITIAN}

Eksplorasi dan pengambilan sampel dilakukan di lima kecamatan (Lembor, Lembor Selatan, Komodo, Ndoso dan Welak) Kabupaten Manggarai Barat, Flores (Lampiran 1). Penelitian telahdilakukan dari bulan Februari-Juli 2016, pengamatan karakter anatomi daun dilakukan di Laboratorium Struktur Perkembangan Tumbuhan, Program Studi Biologi, Fakultas Matematika dan Ilmu Pengetahuan Alam, Universitas Udayana

Cara pengambilan sampel sebagai berikut: setiap ragam diambil 3 individu, untukkarakterisasi morfologi diamati dan diukur batang, daun, buah sesuai pedoman IPGR dan Buku Pusat Perlindungan Varietas Tanaman (PPVT 2007)

Karakteristik Morfologi (23 karakter) diantaranya yaitu ukuran pangkal batang, bentuk mahkota daun, warna pelepah, ukuran pelepah, ketebalan pelepah, lebar pelepah, jumlah anak daun, Panjang anak daun, lebar anak daun, tangkai bunga, rangkaian bunga, diameter tangkai bunga, jumlah tangkai yang ada bunga betina, jumlah tangkai yang tanpai bunga betina, ukuran tangkai yang ada bunga betina, jumlah tangkai bunga dalam satu pohon, jumlah buah, warnabuah, bentuk buah, bobot buah, bentuk biji, bobot biji, ketebalan tempurung, banyaknya air kelapa, bobot daging buah, ketebalan daging buah, jumlah tandan buah per pohon dan jumlah buah pertandan.

Untuk pengamatan anatomi masing-masing pohon diambil 10 irisan lintang dan bujur daun muda, jadi dari masig-masing ragamada 30 irisan yang diamati. Pengamatan digunakan microskop Olympus dan pengukuran menggunakan Optik lab dan Image raster. Karakter anatomi yang diamati yaitu tebal daun, jumlah lapisan, jaringan penyusun, jaringan epidermis atas dan bawah, ada/tidaknya trikoma, jumlah trikoma,jumlah berkas pengangkut, tebal kutikula atas dan bawah, jumlah stomata, bentuk stoma, panjang stomata, lebar stomata, panjang sel penghubung,
Lebar sel penghubung, bentuk sel tetangga, Panjang sel tetangga dan lebar sel tetangga.

Hasil pengamatan morfologi dan anatomi berupa data kualitatif dan kuantitatif untukmembuat kunci, kemudian diskor disajikan dalam bentuk tabel OTU (Operation Taksonomy Unit) untuk membuat dendogram dengan program Minitab vis 14. Dendogram digunakan untuk menganalisis hubungan kekerabatan. Untuk mengetahui manfaat dari tanaman kelapa dilakukan wawancara dengan pemilik dari masing-masin tanaman kelapa.

\section{HASIL}

Hasil eksplorasi keragaman tanaman kelapa (Cocos nucifera L.) famili Arecaceae) yang terdapat di Kabupaten Manggarai Barat didapatkan satu kelompok kelapa berdasarkan kegunaannya, yaitu kelapa atau Nio(bahasa Manggarai) yang umum digunakan untuk membuat bahan makanan dan kopra untuk dapat menghasilkan minyak, baik itu minyak untuk pengganti minyak goreng maupun minyak untuk obat-obatan yang dicampurkan dengan tanaman ataupun akar tanaman sehingga dapat digunakan sebagai minyak pijat/urut. Dari hasil eksplorasi kelapa didapatkan 8 ragam tanaman kelapa yaitu kelapa (nio) Taak Ngoel, nio Ndereng, nio Bakok, nio Kuning, nio Kuse, nio Lolo, nio Sangon, dannio Taak Tua.

Berdasarkan hasil penelitian dari 8 ragam kelapa yang ditemukan di manggarai Barat-Flores, ada beberapa ragam kelapa dari hasil penelitian Yasa dan Kriswiyanti (2016) yang memiliki kesamaan dengan tanaman kelapa yang ada di Manggarai Barat yaitu kelapa/Nio Taak Ngoel sama dengan kelapa Gadang, Nio Kuning sama dengan kelapa Gading Genjah yang memiliki kesamaan karakterisasi morfologiyaitu dari bentuk buah dan warna buah.

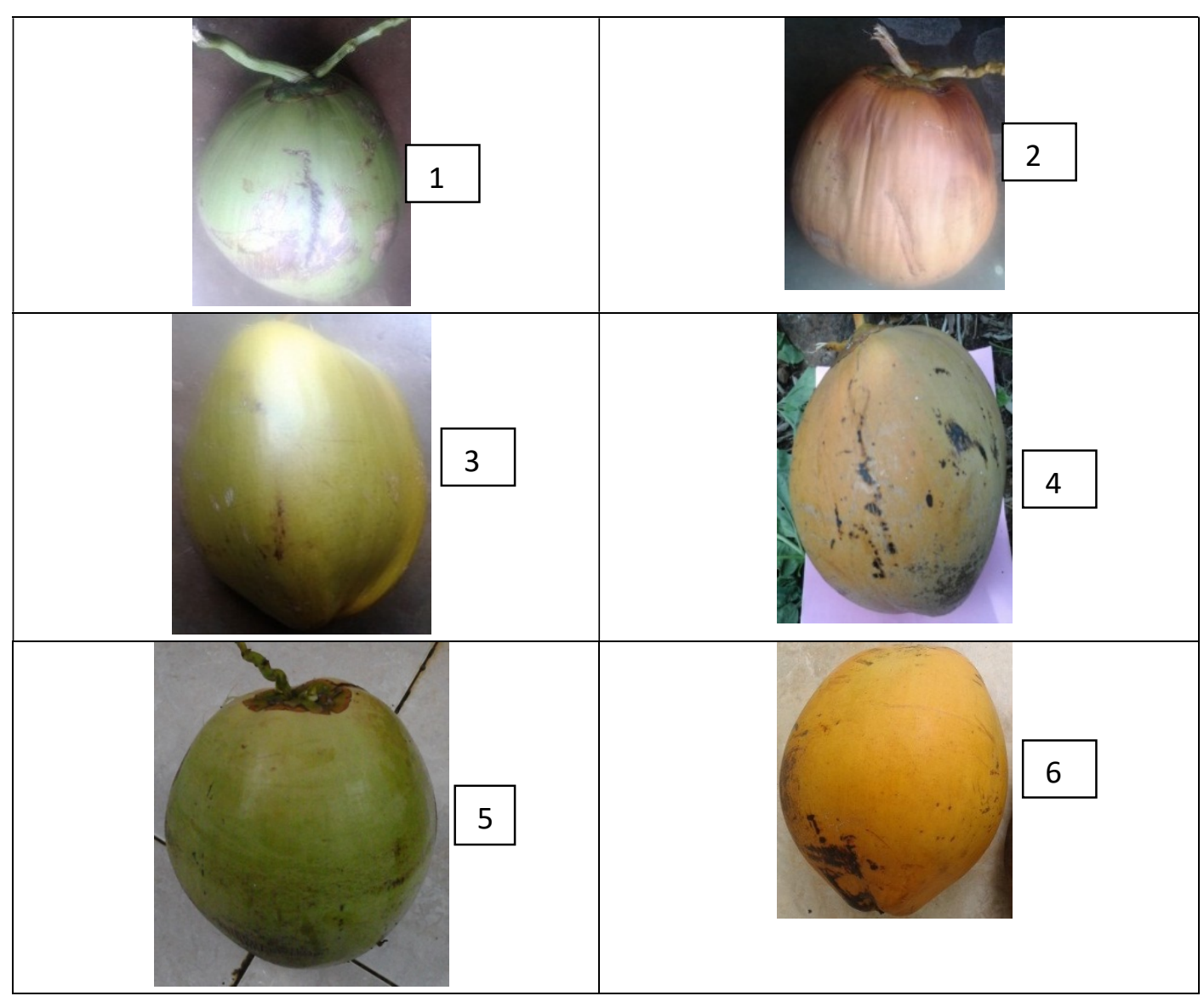




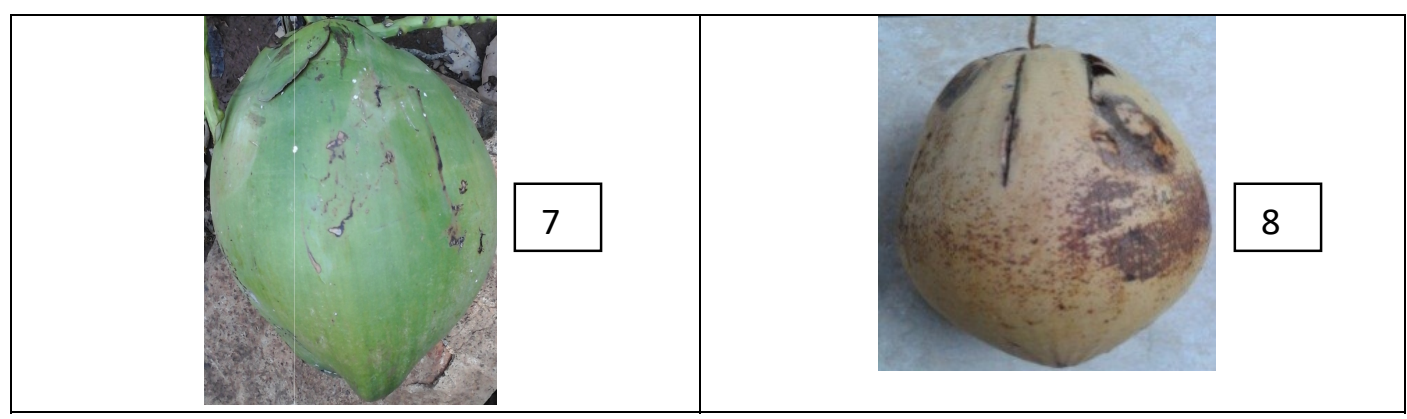

Gambar 1. Bentuk dan Warna Buah Kelapa (Cocos nucifera L.) di Manggarai Barat Keterangan : nio Taak Tua(1), nio kuse (2), nio Lolo (3), nio Ndereng (4), nio Taak Ngoel (5), nio Kuning (6), nio Sangon (7), nio Bakok (8)

Hubungan Kekerabatan Ragam Kelapa (Cocos nucifera L.) di Kabupaten Manggarai Barat-Flores Berdasarkan Karakteristik Morfologi dan Anatomi Daun

Hubungan Kekerabatan Ragam Kelapa (Cocos nucifera L.) antara Morfologi dan Anatomi. Berdasarkan karakter morfologi dan anatomi hubungan kekerabatan ragam kelapa di Kabupaten Manggarai Barat mempunyai tingkat kemiripan paling rendah $19,3 \%-32,1 \%$. Pada tingkat kemiripan $32,1 \%$ dari masing-masing ragam terpisah menjadi 2 kelompok (cluster)yaitu:

Kelompok I : terdiri dari kelapa Nio Kuse, Taak Tua, Sangon

Kelompok II : terdiri dari Nio Bakok, Taak Ngoel, Kuning, Lolo dan Lolo

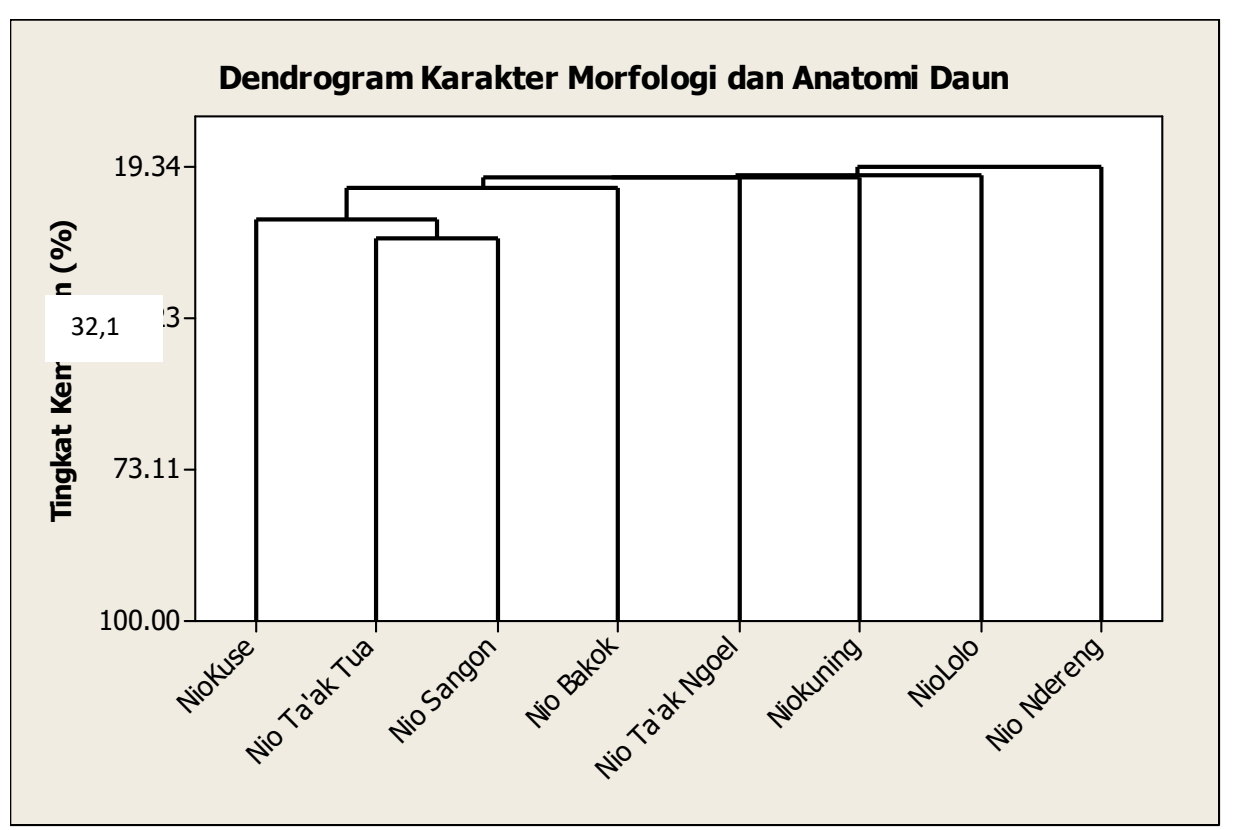

Gambar 2. Dendogram Ragam Kelapa (Cocos nucifera L.) Berdasarkan Karakter Morfologi dan Anatomi

\section{PEMBAHASAN}

Karakteristik Berdasarkan Morfologi dan Anatomi daun Ragam Kelapa (Cocos nucifera $L$.) di Kabupaten Manggarai Barat, Flores

Hasil penelitian menunjukkan bahwa dari 8 individu kelapa (Cocos nucifera L.) yang ditemukan di Kabupaten Manggarai Barat, memiliki karakter morfologi yang dapat memperlihatkan perbedaan antara individu. Dari sekian banyak karakteristik morfologi dari hasil penelitian ragam kelapa (Cocos nucifera L.) dapat dilihat bahwa karakteristik yang sangat menonjol ada pada ragam kelapa di kabupaten Manggarai Barat-Flores yaitu ada/tidak ada bole dan warna pada kulit buah.

Tanaman kelapa (Cocos nucifera L.) di kabupaten Manggarai Barat-Flores yang ditemukan, dapat dibedakan antara kelapa Dalam dan kelapa Genjah. Ragam kelapa (Cocos nucifera L.) yang termasuk Kelapa Dalam (Cocos nucifera var. typica). Tinggi dapat mencapai $30 \mathrm{~m}$. Buah besar dengan berat $1,5-2 \mathrm{~kg}$. Berbuah setelah berumur $6-7$ tahun. Kelapa varietas ini banyak ditanam oleh penduduk atau tumbuh liar di daerah pantai. Buah kelapa dalam memiliki variasi pada warna buah dan rasa air buahnya: a) kelapa hijau (viridis), buah kelapa berwarna hijau; b) kelapa merah (rubescens), buah kelapa berwarna; c) kelapa dalam besar (macrocarpa), buah kelapa berukuran besar; d) kelapa dalam air manis (saccharina).Kelapa Dalam dari penelitian ini yaitu nio Lolo, nio Ndereng, nio Sangon, nio Taak ngoel, nio Taak Tua dan nio Bakok.

Kelapa genjah (Cocos nucifera var. nana). Kata nana yang artinya pendek atau kerdil. Tinggi batang hanya mencapai $5 \mathrm{~m}$. Berbuah setelah berumur 3-4 tahun. Buah kelapa genjah umumnya tidak terlalu besar, yaitu $0,9-1,2 \mathrm{~kg}$. Kelapa genjah juga memiliki variasi dalam warna buah dan bentuk buahnya: a) kelapa genjah gading (ebunea), buah kelapa berbentuk bulat berwarna gading atau kuning; b) kelapa genjah raja (regia), buah kelapa berbentuk lonjong dan besar, berwarna jingga; c) kelapa genjah jingga (prefiosa), buah kelapa berbentuk lonjong, berwarna jingga; d) kelapa genjah puyuh (pumila), buah kelapa berukuran kecil lonjong, berwarna hijau.Hasil penelitian ini, ragam kelapa (Cocos nucifera L.) yang termasuk kelapa genjah yaitu nio Kuse dan nio Kuning.

Hubungan Kekerabatan Ragam Kelapa (Cocos nucifera L.) di Kabupaten Manggarai Barat-Flores Berdasarkan Karakteristik Morfologi dan Anatomi

Berdasarkan karakter morfologi dari 8 ragam kelapa (Cocos nucifera L.) di kabupaten Manggarai Barat 
memiliki perbedaan pada ada/tidak adanya bole, bentuk buah,warna buah, ukuran buah, tebal tangkai daun, tebal daging buah, bentuk biji, jumlah buah per pohon/ per tandan, panjang daun, lebar daun, lingkara batang $20 \mathrm{~cm}$ dari permukaan tanah, $150 \mathrm{~cm}$ dari permukaan tanah dan lingkaran batang pada 11 ruas. Berdasarkan hal tersebut diatas didapatkan dendogram (Gambar 2) yang menyimpulkan bahwa : berdasarkan karakter morfologi, tingkat kemiripandapat di bedakan menjadi 2 kelompok (cluster)yaitu kelompok pertama Nio Kuse, Taak Tua, Kuning dan Taak Ngoel memiliki tingkat kemiripan $32,1 \%$, keempat jenis ragam kelapa (Cocos nucifera L.) mempunyai beberapa persamaan karakter diantaranya ukuran daun, lebar pelepah, bobot daging, tebal daging buah. Kelompok kedua yaitu nio Ndereng, Bakok, Sangon dan Lolo dengan tingkat kemiripan 26,43\%, yang memiliki karakter yang sama yaitu ukuran daun, lebar pelepah, jumlah anak daun dan jumlah buah per pohon. Hal ini menyatakan bahwa dari hasil pengamatan secara morfologi dengan tingkat kemiripan paling tinggi yaitu $32,1 \%$ dari masing-masing delapan ragam. Sedangkan yang lain tingkat kemiripannya tidak terlalu jauh memisahkan antara masing-masing ragam.

Hasil pengamatan anatomi daun dari 8 jenis ragam kelapa (Cocos nucifera L.) dapat menunjukkan adanya keanekaragaman pada jumlah stomata, ukuran stomata, lebar stomata, panjang stomata, bentuk stomata, lebar porus, panjang porus, jumlah lapisan atas,jumlah lapisan bawah, dan jumlah trikoma. Berdasarkan karakter anatomi daun dari masing-masing ragam kelapa di bagi menjadi 2 kelompok (Gambar 2). Kelompok pertama nio Kuse, Taak Tua,Taak Ngoel dan Sangon memiliki tingkat kemiripan 50,8 \%, dengan persamaan karakter yaitu jumlah lapisan, jumlah epidermis bawah, jumlah berkas pengangkut. Kelompok kedua, Bakok, Kuning, Lolo dan Ndereng dengan tingkat kemiripan 26,6 \% dengan persamaan karakter masing-masing mempunyai tebal lapisan, jumlah epidermis atas, jumlah trikoma, panjang stomata, panjang porus, jumlah stomata. Hal ini menunjukan bahwa tingkat kemiripan paling tinggi yaitu $51,8 \%$, sehingga masing-masing kultivar terpisah.

Hasil penggabungan berdasarkan karakter morfologi dan anatomi memiliki tingkat kemiripan 19,3 $\%$ yang dikelompokkan menjadi 2 cluster yaitu kelompok pertama Nio Kuse, Taak Tua, dan Sangon tingkat kemiripan 32,1 \%. Kelompok kedua, Bakok, Taak Ngoel, Kuning, Lolo dan Ndereng dengan tingkat kemiripan 19,3 $\%$. Berdasarkan penggabungan antara karakter morfologi dan anatomi menunjukkan kecendrungan yang hampir sama dengan hasil karakter morfologi dan anatomi. Hasil penelitian menunjukkan bahwa dari karakter morfologi bobot buah paling berat yaitu nio Sangon $\pm 2,6 \mathrm{~kg}$, bobot daging yaitu nio Taak Tua $\pm 1,7 \mathrm{~kg}$, jumlah tandan nio Taak Tua \pm 6 tandan, jumlah buah per tandan nio Kuse dan Lolo \pm 13 biji, jumlah buah per pohon nio Taak Tua \pm 21 biji dan tebal serabut nio Bakok $\pm 2,9 \mathrm{~cm}$.

Hubungan kekerabatan antar jenis dari 8 jenis kelapa (Cocos nucifera L.) di kabupaten Manggarai Barat terbilang rendah karena menunjukkan tingkat kemiripan yaitu 19,3\%, yang mana menurut Singh (1999) jika angka kemiripan diatas/sama dengan 60\% maka dapat dikatakan tanaman tersebut memiliki kekerabatan yang dekat.

\section{Manfaat Tanaman Kelapa (Cocos nucifera L.) di Kabupaten Manggarai Barat}

Menurut Mahmud dan Ferry (2005) tanaman kelapa disebut sebagai tanaman serba guna, karena dari akar, daun, bunga, buah, sampai biji memiliki manfaat. Berdasrkan hasil penelitian yang dilakukan di Kabupaten Manggarai Barat-Flores, tanaman kelapa (Cocos nucifera L.) yang ditemukan semuanya mempunyai manfaat yang sama baik dari daun, batang, buah, tempurung dan juga serabut dari buah. Masyarakat di Kabupeten Manggarai Barat-Flores dapat memanfaatkan tanaman kelapa (Cocos nucifera L.) ini dapat membantu perekonomian.

\section{SIMPULAN}

Berdasarkan karakteristik morfologi dan anatomi daun, dapat disimpulkan bahwa : ditemukan 8 ragam kelapa (Cocos nucifera L.) tersebut yaitu Nio Kuse, Nio Sangon, Nio Taak Tua, Nio Taak Ngoel, Nio Ndereng, Nio Kuning, Nio Lolo, Bakok. Ragam kelapa (Cocos nucifera L.) di Manggarai Barat-Flores memiliki type stomata Parasitik. Karakter morfologi bobot buah paling berat yaitu nio Sangon $\pm 2,6 \mathrm{~kg}$, bobot daging yaitu nio Taak Tua $\pm 1,7 \mathrm{~kg}$, jumlah tandan per pohon (nio Taak Tua \pm 6 tandan), jumlah buah per tandan (nio Kuse dan nio Lolo \pm 13 biji), jumlah buah per pohon (nio Taak Tua \pm 21 biji) dan tebal serabut (nio Bakok $\pm 2,9 \mathrm{~cm}$ ). Tanaman kelapa (Cocos nucifera L.) masing-masing bagian dari tanaman kelapa mempunyai manfaat dan nilai ekonomi bagi masyarakat setempat.

\section{SARAN}

Di harapkan penelitian tanaman kelapa (Cocos nucifera L.) di Manggarai Barat-Flores dapat dilakukan penelitian lebih lanjut sehingga dapat menemukan lebih banyak ragam.

\section{DAFTAR PUSTAKA}

Allorerung, D., Mahmud, Z. dan Prastowo, B. 2006. Peluang Kelapa Untuk Pengembangan Produk Kesehatan dan Bioenergi. Pusat Penelitian dan Pengembangan Perkebunan, Bogor.

Deptan RI PPVT. 2007. Panduan Pengujian Individual Kebaruan. Keunikan. Keseragaman dan kestabilan Kelapa. Coconut (Cocos nucifera L.). PPVT/PPI/33/I Tanggal 16 juni 2007

International Board for Plant Genetic Resources (IBPGR). 1992. Discriptors for Coconut", Rome, Italy.

Kriswiyanti, E. 2014. Karakteristik Ragam Kelapa (Cocos nucifera L.) di Bali Berdasarkan Morfologi, Anatomi dan Molekuler. Universitas Udayana: Denpasar

Mahmud, Z. dan Ferry, Y. 2005. Prospek Pengolahan Hasil Samping Buah Kelapa. Jurnal Pusat Penelitian dan Pengembangan Perkebunan, 4(2), Bogor: Penelitian dan Pengembangan Perkebunan.

Maskromo, I. 2000. Karakterisasi Kelapa Semi Dalam Solo Asal Buol Sulawesi Tengah. Balai Penelitian Tanaman Kelapa dan Palm Lain Manado. Zuriat, $11(2): 1-8$

Setyamidjaja, Djoehana. 2008. Bertanam Kelapa. Kanisius.Yogyakarta. Jurnal Simbiosis I (2) 102101 


\section{DIRECTORY OF
OPEN ACCESS}

Maret 2018

Yasa,I.W.S dan E. Kriswiyanti 2016. Karakterisasi dan Distribusi Kelapa Madan di kecamatan Manggis Kabupaten Kanrangasem, Bali. Jurnal Simbiosis IV (1: 10-15) 